\title{
Physician satisfaction with hospital clinical laboratory services in Aden Governorate, Yemen, 2009
}

\author{
N. Mujahed Adulkader ${ }^{1}$ and B.E. Garcia Triana ${ }^{2}$
}

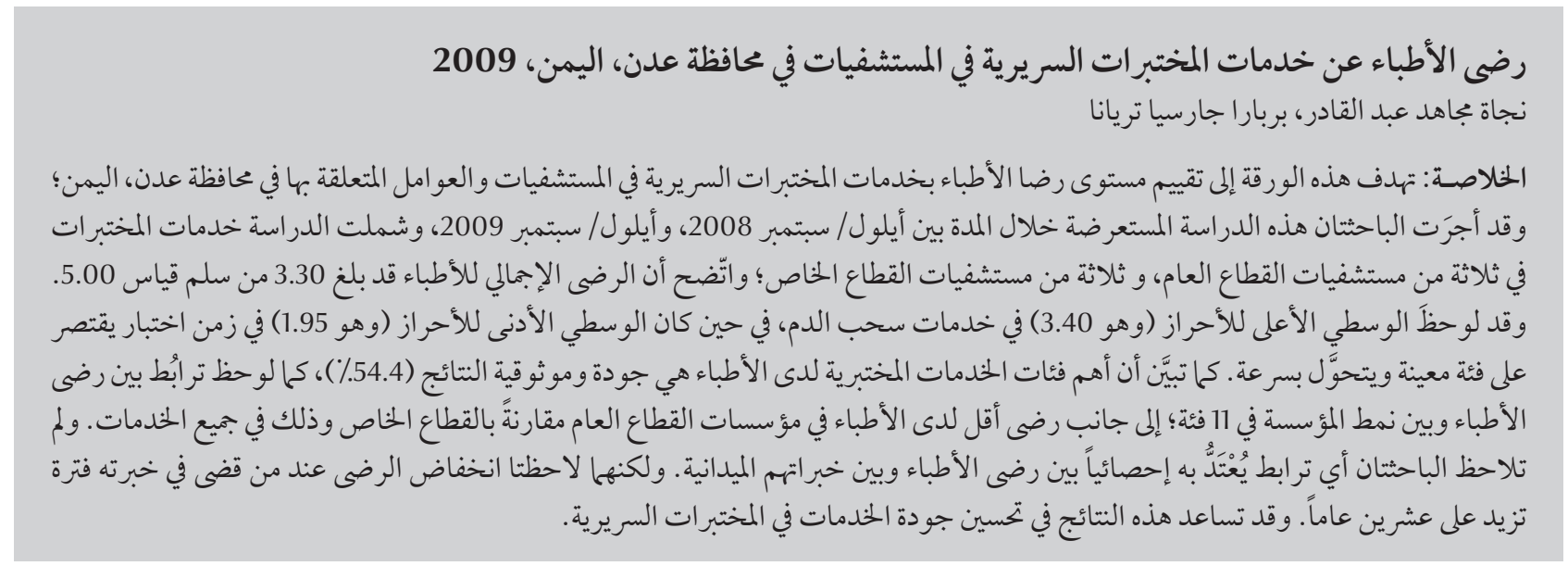

ABSTRACT To evaluate the level of physicians' satisfaction with hospital clinical laboratory services and related factors in Aden Governorate, we carried out this cross-sectional study during September 2008-September 2009. Satisfaction with laboratory services of 3 public and 3 private hospitals was assessed. The overall physician satisfaction was 3.30 out of 5.00. The highest mean score (3.40) was observed for phlebotomy services, while the lowest mean score (1.95) was for esoteric test turnaround time. The most important laboratory service category for the physicians was quality and reliability of the results (54.4\%). An association was observed between physician satisfaction and institution type in 11 categories, with lower satisfaction for public compared to private institutions for all services. No statistically significant association was observed between physician satisfaction and experience in the field. Lower satisfaction was observed among those with more than 20 years experience. Our findings may help to improve the quality of clinical laboratory services.

Satisfaction des médecins en matière de services fournis par les laboratoires cliniques hospitaliers dans le Gouvernorat d'Aden (Yémen) en 2009

RÉSUMÉ Afin d'évaluer le niveau de satisfaction des médecins en matière de services fournis par les laboratoires cliniques hospitaliers et les facteurs associés dans le gouvernorat d'Aden, nous avons mené la présente étude transversale entre septembre 2008 et septembre 2009. Le niveau de satisfaction pour les services de laboratoire a été évalué dans trois hôpitaux publics et trois hôpitaux privés. La satisfaction globale des médecins était de 3,30 sur 5,00. Le score moyen le plus élevé $(3,40)$ concernait les services de phlébotomie, alors que le score moyen le plus faible $(1,95)$ a été attribué au temps de réponse pour les tests spécialisés. Les critères des services de laboratoire les plus importants pour les médecins étaient la qualité et la fiabilité des résultats (54,4\%). Une association a été observée entre la satisfaction des médecins et le type d'institution pour 11 critères, le degré de satisfaction le plus faible ayant été attribué aux laboratoires publics par rapport aux laboratoires privés, et ce pour tous les services. Aucune association statistiquement significative n'a été constatée entre la satisfaction des médecins et l'expérience sur le terrain. Les médecins ayant plus de 20 ans d'expérience étaient moins satisfaits que leurs collègues. Nos résultats pourraient contribuer à améliorer la qualité des services des laboratoires cliniques.

'Departement of Physiological Sciences, Faculty ofMedicine, University of Aden, Aden, Yemen (Correspondence to N. Mujahed: najatakader@ yahoo.com).

${ }^{2}$ Department of Morphophysiology, Faculty of Dentistry, Medical University of Havana, Havana, Cuba.

Received: 03/08/11; accepted: 12/12/11 


\section{Introduction}

Satisfaction is an important element of the quality of services, including health services: a high quality organization meets customer's needs. One approach assumes that, in the clinical laboratory, managers know what customers want and directly set out measures of laboratory performance in each specific area. Another approach considers that quality measurement is the assessment of customer satisfaction with the services provided by the laboratory. Each approach has its advantages for assessing quality. Direct assessment of local performance helps managers understand whether it is improving and how it compares to published norms. On the other hand, customer satisfaction assessment helps to better define the real expectations of the ordinary customers of a particular laboratory $[1,2]$.

Physicians are the primary external customers of laboratory services and their opinions are essential components in providing laboratory managers with opportunities to identify areas for improvement [3].

Nowadays, assessing customer satisfaction with laboratory services is considered an important component of a laboratory quality assurance programme, and is required for accreditation by the College of American Pathologists and the Joint Commission on Accreditations for Healthcare Organizations. Both agencies are located in the United States of America and have power for accrediting laboratories [3].

During out daily work, both in the university and in hospitals, we have noticed there are a numerous complaints about the quality of clinical laboratory services among the population and physicians in Aden Governorate, however, no data have been published about these issues. This study is the first to investigate these matters and our findings will be useful in designing and implementing measures to improve the quality of clinical laboratory services in Aden. Any resulting improvements could also be extended to other laboratories in the country.

\section{Methods}

This was an observational, crosssectional study, carried out from September 2008 to September 2009 to assess the level of physician satisfaction with the laboratory services of 6 hospitals ( 3 public and 3 private) in Aden Governorate. The laboratories were selected by quota sampling in regard to the number of procedures carried out per day and the number of technicians in each laboratory. The subjects of this study included all the physicians working in the selected hospitals and who were willing to participate and complete the questionnaire attached by written consent. Physicians in training (interns) were excluded.

The sample size for the assessment of physician satisfaction with clinical laboratory services was calculated by using Epi Info, 3.5.1 (StatCalc). Accordingly, from a total population of 452 , considering an expected frequency of $50 \%$ and a confidence interval of $95 \%$, the calculated sample size for the physicians was 207. This sample was proportionally distributed among the selected hospitals, according to the total number of physicians, using the formula [4]:

Institute sample size $=$ (no. of customers in the institute/total no. of customers in all institutions) $\times$ total sample size.

Simple random sampling was applied for the selection of physicians in each institution.

For the assessment of satisfaction, we developed a self-administered, Arabic language questionnaire through consultation with experts in the field, and taking into account what had been published previously $[3,5]$. This was used to assess the level of overall satisfaction and the satisfaction with 11 specific aspects of clinical laboratory services such as courier services, routine and stat turnaround times (TAT), esoteric test TAT, phlebotomy services (central phlebotomy services for each clinical laboratory), courtesy of clinical laboratory staff, adequacy of test menu, quality and reliability of results (congruence between the clinical laboratory results and signs, symptoms and response to treatment), critical value notification, clinical report format, and notification about new investigations. Services were rated on a scale of 1 to $5(1=$ poor, $2=$ below average, 3 = average, 4 = good, and 5: = excellent).

The relationship between the level of physician satisfaction together with the institution type (public or private), and experience in the work field $\leq 10$ years, $11-20$ years and $>20$ years) was also assessed.

Through an open-ended question, physicians were asked to indicate which of the 11 aspects of service was the most important to them.

The collected data were processed into an electronic database for statistical analysis using SPSS, version 16.0, and Epi Info 2007 data analysis programs and STATISTICA, version 5.5. Descriptive analysis was used (frequencies, percentages, means and standard deviations with a confidence interval of $95 \%$ ) and a study power of 80 . The Kruskal-Wallis test was also used to test for statistically significant relationships between physician satisfaction and clinical laboratory services, institution type and experience in the work field. Statistical significance was considered as $P<0.05$.

Three composite satisfaction measures were used for each laboratory $[3,5]$ :

- Overall mean satisfaction score $=$ (No. of excellent ratings $\times 5)+($ No. of good ratings $\times 4)+($ No. of average ratings $\times 3)+($ No. of below average ratings $\times 2)+($ No. of poor ratings $x$ 1) for overall satisfaction/total No. of ratings (1-5) for overall satisfaction with laboratory services $[3,5]$. 
- Percentage of excellent or good ratings $=($ No. of excellent or good ratings for specific laboratory service category $\times 100) /$ total No. of ratings $(1-5)$ for specific laboratory service category.

- Percentage of below average or poor ratings $=($ No. of below average or poor ratings for specific laboratory service category $\times 100$ )/total No. of ratings (1-5) for specific laboratory service category.

\section{Results}

A total of 207 physician surveys were distributed to the 6 institutions under study; 161 surveys were returned giving a response rate of $78 \%$. The majority (80.7\%) of our sample of 161 physicians were from public institutions (Table 1). In regard to experience in the work field, $64.6 \%$ had worked for $\leq 10$ years.

The mean overall satisfaction score was calculated for each participating institution separately. The overall mean for physician satisfaction score ranged from 2.42 for the 10th percentile to 4.00 for the 90th percentile; the median score for physicians was 3.48 (Table 2).

The aggregate number of ratings for physician satisfaction was calculated. For 3 categories, the highest rating was "good": phlebotomy services (44.7\%), courtesy of clinical laboratory staff (38.5\%) and clinical report format (27.3\%) (Table 3). Quality and reliability of results had "below average" as the highest rating (30.4\%). The highest proportion of "poor" ratings was for the esoteric test TAT (55.3\%) and notification about the new investigations (36.0\%).

\begin{tabular}{|c|c|c|}
\hline \multicolumn{3}{|c|}{$\begin{array}{l}\text { Table } 1 \text { Characteristics of physicians }(n=161) \text { who participated in the study, Aden, } \\
2009\end{array}$} \\
\hline Characteristic & No. & $\%$ \\
\hline \multicolumn{3}{|l|}{ Institution type } \\
\hline Public & 130 & 80.7 \\
\hline Private & 31 & 19.3 \\
\hline \multicolumn{3}{|c|}{ Experience (years) } \\
\hline$\leq 10$ & 104 & 64.6 \\
\hline $11-20$ & 40 & 24.8 \\
\hline$>20$ & 17 & 10.6 \\
\hline
\end{tabular}

The highest mean score was for phlebotomy services (3.40; standard deviation 1.13), while the lowest was for esoteric test TAT (1.95; standard deviation 1.21) (Table 3).

The most important laboratory service category was quality and reliability of results (54.4\%), followed by routine TAT, stat TAT and critical value notification (8.2\%) (Table 4).

The ratings for physician satisfaction were calculated for all the service categories according to institution type and the relationship was statistically significant $(P<0.05)$ for 11 of the services categories out of the 12 items under study (Table 5). Below average/poor ratings (less satisfaction) were observed more in public institutions than in private ones. Phlebotomy services showed the same tendency $(23.1 \%$ for public and $6.5 \%$ for private), but the relationship was not statistically significant $(P \geq$ $0.05)$. Overall services also followed this trend, $46.2 \%$ for public laboratories and $6.5 \%$ for private (Table 5 ).

No statistically significant association $(P \geq 0.05)$ was observed between physician satisfaction and duration of work in any of the service categories, but the results showed a decrease in the proportion of excellent/good ratings and higher proportions of below average/poor ratings (less satisfaction) among those with $>20$ years experience in the work field for some of the service categories: esoteric test TAT, test menu adequacy, notification about the new investigations and overall services (Table 6).

\section{Discussion}

Measurement of customer satisfaction brings customer preferences into the quality assessment process and corrects false assumptions about particular aspects of service, which customers value most. Today, assessing customer satisfaction with laboratory services is considered as an important component for improving the identified areas. Physicians are the primary customers of laboratory services and the most important and their satisfaction is considered an important factor influencing the quality of health care provision, patient compliance, and costs to health care systems. Dissatisfaction leads to an increase in the turnover of physicians and early retirement, which has a negative impact on continuity and quality of health care $[3,6,7]$.

\begin{tabular}{|c|c|c|c|c|c|c|}
\hline \multirow[t]{2}{*}{ Factor } & \multirow[t]{2}{*}{ Mean } & \multicolumn{5}{|c|}{ All institutions, percentiles } \\
\hline & & 10th & 25th & $\begin{array}{c}\text { 50th } \\
\text { (median) }\end{array}$ & 75th & 90th \\
\hline Overall mean physician satisfaction score & 3.30 & 2.42 & 2.49 & 3.48 & 3.94 & 4.00 \\
\hline
\end{tabular}




\begin{tabular}{|c|c|c|c|c|c|c|c|c|c|c|c|}
\hline \multirow[t]{2}{*}{ Service category } & \multicolumn{2}{|c|}{ Excellent } & \multicolumn{2}{|c|}{ Good } & \multicolumn{2}{|c|}{ Average } & \multicolumn{2}{|c|}{ Below average } & \multicolumn{2}{|c|}{ Poor } & \multirow{2}{*}{$\begin{array}{c}\text { Mean (SD) } \\
\text { score }\end{array}$} \\
\hline & No. & $\%$ & No. & $\%$ & No. & $\%$ & No. & $\%$ & No. & $\%$ & \\
\hline Phlebotomy services & 20 & 12.4 & 72 & 44.7 & 37 & 23.0 & 16 & 9.9 & 16 & 10.0 & $3.40(1.13)$ \\
\hline $\begin{array}{l}\text { Courtesy of clinical } \\
\text { laboratory staff }\end{array}$ & 8 & 5.0 & 62 & 38.5 & 56 & 34.8 & 22 & 13.7 & 13 & 8.0 & $3.19(1.00)$ \\
\hline Routine TAT & 6 & 3.7 & 47 & 29.2 & 57 & 35.4 & 34 & 21.1 & 17 & 10.6 & $2.94(1.03)$ \\
\hline Courier services & 24 & 14.9 & 31 & 19.2 & 50 & 31.1 & 32 & 19.9 & 24 & 14.9 & $2.99(1.26)$ \\
\hline Test menu adequacy & 6 & 3.8 & 43 & 26.7 & 49 & 30.4 & 38 & 23.6 & 25 & 15.5 & $2.80(1.11)$ \\
\hline Clinical report format & 13 & 8.1 & 44 & 27.3 & 40 & 24.8 & 35 & 21.7 & 29 & 18.0 & $2.86(1.23)$ \\
\hline $\begin{array}{l}\text { Quality and reliability of } \\
\text { results }\end{array}$ & 9 & 5.6 & 34 & 21.1 & 46 & 28.6 & 49 & 30.4 & 23 & 14.3 & $2.73(1.11)$ \\
\hline Stat TAT & 2 & 1.2 & 39 & 24.2 & 54 & 33.5 & 34 & 21.1 & 32 & 20.0 & $2.66(1.09)$ \\
\hline Critical value notification & 11 & 7.0 & 26 & 16.1 & 47 & 29.2 & 44 & 27.3 & 33 & 20.4 & $2.61(1.17)$ \\
\hline $\begin{array}{l}\text { Notification about the new } \\
\text { investigations }\end{array}$ & 11 & 6.8 & 26 & 16.1 & 31 & 19.3 & 35 & 21.7 & 58 & 36.0 & $2.36(1.30)$ \\
\hline Esoteric test TAT & 3 & 1.9 & 24 & 14.9 & 24 & 14.9 & 21 & 13.0 & 89 & 55.3 & $1.95(1.21)$ \\
\hline Overall services & 2 & 1.2 & 41 & 25.5 & 56 & 34.8 & 41 & 25.5 & 21 & 13.0 & $2.76(1.01)$ \\
\hline
\end{tabular}

$S D=$ standard deviation

TAT = turnaround time.

The overall mean satisfaction score (3.30) was lower than what has been reported by Jones et al. (4.0) [3] and Zarbo, Nakleh and Walsh (4.4) [6] in the 2 previous Q-Probes studies related to physician satisfaction with clinical laboratory services. Our findings are consistent with the previous studies only in terms of methodology, but differ from them greatly in terms of the number of institutions and number of physicians involved. It should be noted that the two previous studies included a large number of laboratories and physicians from different developed countries, where special programmes for assessing customer satisfaction are available and most of those institutions are licensed by the Joint Commission on Accreditation of Healthcare Organizations and the College of American Pathologists $[3,6]$.

We take this opportunity to consider that Yemen is now ranking 138 out of 179 countries in the UNDP Human Development Index [8], compared with in the ranking for the previous year (153). Despite this progress, Yemen remains one of the least developed countries in the world. On the other hand, the World Health Organization has classified Yemen, in terms of performance of the health system, as 120 among the 190 member states [9].

During our data collection we found no party responsible for monitoring the laboratories, in terms of compliance with international standards, for the establishment of an integrated clinical laboratory, for provision of automated equipment and qualified technicians, and for occupational safety of patients and workers in Aden Governorate.

Table 4 Distribution of hospital clinical laboratory service categories deemed most important by physicians in Aden, 2009

\begin{tabular}{lcc}
\hline Service category & No. & $\%$ \\
& 3 & 2.0 \\
Courier services & 13 & \\
Test TAT & 13 & 8.2 \\
Routine TAT & 5 & 8.2 \\
Stat TAT & & 3.2 \\
Esoteric test TAT & 2 & \\
Phlebotomy & 7 & 1.3 \\
Phlebotomy services & & 4.4 \\
Courtesy of clinical laboratory staff & 2 & 1.3 \\
Laboratory information system & 86 & 54.4 \\
Test menu adequacy & 13 & 8.2 \\
Quality and reliability of results & 1 & 0.6 \\
Critical value notification & 1 & 0.6 \\
Clinical report format & 12 & 7.6 \\
Notification of new investigations & & \\
Overall services &
\end{tabular}

$T A T=$ turnaround time. 


\begin{tabular}{|c|c|c|c|c|c|c|}
\hline \multirow[t]{2}{*}{ Service category } & \multicolumn{2}{|c|}{$\begin{array}{l}\text { Excellent/good } \\
\text { Institution }\end{array}$} & \multicolumn{2}{|c|}{$\begin{array}{c}\text { Average } \\
\text { Institution }\end{array}$} & \multicolumn{2}{|c|}{$\begin{array}{c}\text { Below average/ poo } \\
\text { Institution }\end{array}$} \\
\hline & $\begin{array}{l}\text { Public } \\
\text { (\%) }\end{array}$ & $\begin{array}{c}\text { Private } \\
(\%)\end{array}$ & $\begin{array}{l}\text { Public } \\
(\%)\end{array}$ & $\begin{array}{c}\text { Private } \\
\text { (\%) }\end{array}$ & $\begin{array}{c}\text { Public } \\
(\%)\end{array}$ & $\begin{array}{c}\text { Private } \\
\text { (\%) }\end{array}$ \\
\hline Courier services* & 19.2 & 96.8 & 38.5 & 0.0 & 42.3 & 3.2 \\
\hline Routine turnaround time* & 23.1 & 74.2 & 38.5 & 22.6 & 38.5 & 3.2 \\
\hline Stat turnaround time* & 21.5 & 41.9 & 28.5 & 54.8 & 50.0 & 3.2 \\
\hline Esoteric test turnaround time* & 3.1 & 74.2 & 13.8 & 19.4 & 83.1 & 6.5 \\
\hline Phlebotomy services & 57.7 & 54.8 & 19.2 & 38.7 & 23.1 & 6.5 \\
\hline Courtesy of clinical laboratory staff* & 36.2 & 74.2 & 36.9 & 25.8 & 26.9 & 0.0 \\
\hline Test menu adequacy* & 16.2 & 90.3 & 36.9 & 3.2 & 46.9 & 6.5 \\
\hline Quality and reliability of results* & 11.5 & 90.3 & 33.8 & 6.5 & 54.6 & 3.2 \\
\hline Critical value notification* & 13.8 & 61.3 & 29.2 & 29.0 & 56.9 & 9.7 \\
\hline Clinical report format* & 22.3 & 90.3 & 29.2 & 6.5 & 48.5 & 3.2 \\
\hline Notification of new investigations* & 13.8 & 61.3 & 16.9 & 29.0 & 69.2 & 9.7 \\
\hline Overall services* & 11.5 & 90.3 & 42.3 & 3.2 & 46.2 & 6.5 \\
\hline
\end{tabular}

Percentage calculated by categories of institution type H: Kruskal-Wallis test (chi-squared correspondent).

* Statistically significant, $P<0.05$ (degrees offreedom 2).

So in this situation, the low level of overall mean physician satisfaction is an expected result, and reflects the real quality of clinical laboratories and the services provided in Aden Governorate.
We found the highest mean score for phlebotomy services, while the lowest was for esoteric TAT, similar to findings reported in other studies in the United States of America which evaluated overall physician satisfaction and specific satisfaction of physicians with 15 aspects of clinical laboratory services $[3,5]$. Nearly half of our respondents selected quality and reliability of results, followed by routine TAT and stat TAT as being most important for them. This

\begin{tabular}{|c|c|c|c|c|c|c|c|c|c|}
\hline \multirow[t]{3}{*}{ Service category } & \multicolumn{9}{|c|}{ Experience in work field (years) } \\
\hline & \multicolumn{3}{|c|}{ Excellent/good } & \multicolumn{3}{|c|}{ Average } & \multicolumn{3}{|c|}{ Below average/poor } \\
\hline & $\begin{array}{l}\leq 10 \\
(\%)\end{array}$ & $\begin{array}{c}11-20 \\
(\%)\end{array}$ & $\begin{array}{l}>20 \\
(\%)\end{array}$ & $\begin{array}{l}\leq 10 \\
(\%)\end{array}$ & $\begin{array}{c}11-20 \\
(\%)\end{array}$ & $\begin{array}{l}>20 \\
(\%)\end{array}$ & $\begin{array}{l}\leq 10 \\
(\%)\end{array}$ & $\begin{array}{c}11-20 \\
(\%)\end{array}$ & $\begin{array}{l}>20 \\
(\%)\end{array}$ \\
\hline Courier services & 33.7 & 35.0 & 35.3 & 30.8 & 35.0 & 23.5 & 35.6 & 30.0 & 41.2 \\
\hline Routine TAT & 32.7 & 37.5 & 23.5 & 31.7 & 35.0 & 58.8 & 35.6 & 27.5 & 17.6 \\
\hline Stat TAT & 26.0 & 27.5 & 17.6 & 32.7 & 30.0 & 47.1 & 41.3 & 42.5 & 35.3 \\
\hline Esoteric test TAT & 20.2 & 15.0 & 0.0 & 14.4 & 12.5 & 23.5 & 65.4 & 72.5 & 76.5 \\
\hline Phlebotomy services & 51.0 & 72.5 & 58.8 & 27.9 & 15.0 & 11.8 & 21.2 & 12.5 & 29.4 \\
\hline Courtesy of clinical laboratory staff & 38.5 & 57.5 & 41.2 & 37.5 & 22.5 & 47.1 & 24.0 & 20.0 & 11.8 \\
\hline Test menu adequacy & 29.8 & 37.5 & 17.6 & 31.7 & 27.5 & 29.4 & 38.5 & 35.0 & 52.9 \\
\hline Quality and reliability of results & 23.1 & 42.5 & 11.8 & 26.9 & 25.0 & 47.1 & 50.0 & 32.5 & 41.2 \\
\hline Critical value notification & 23.1 & 22.5 & 23.5 & 34.6 & 20.0 & 17.6 & 42.3 & 57.5 & 58.8 \\
\hline Clinical report format & 33.7 & 37.5 & 41.2 & 27.9 & 15.0 & 29.4 & 38.5 & 47.5 & 29.4 \\
\hline $\begin{array}{l}\text { Notification about the new } \\
\text { investigations }\end{array}$ & 22.1 & 27.5 & 17.6 & 23.1 & 15.0 & 5.9 & 54.8 & 57.5 & 76.5 \\
\hline Overall services & 26.9 & 35.0 & 5.9 & 37.5 & 27.5 & 35.3 & 35.6 & 37.5 & 58.8 \\
\hline
\end{tabular}

Percentage calculated by categories of experience H: Kruskal-Wallis test (chi-squared correspondent).

Degrees of freedom 2.

TAT = turnaround time. 
is similar to what was reported by Jones et al. [3].

Physicians in private institutes showed a higher satisfaction level for 11 of the services provided by the clinical laboratory and for overall services compared with physicians in public institutes. This is similar to what was reported by Mfinanga et al. [10] as well as to what had been predicted. This may be an indication of the quality of services in public laboratories being lower than that in private facilities, which should be a matter for further research.

No association was observed between physician satisfaction and clinical laboratory services and years of experience, but the results showed lower satisfaction for some of the services among those with $>20$ years experience. It is possible that physicians having long experience could have a greater ability to discriminate the quality of services provided and the reliability of the results issued by the laboratory for diagnosis of different diseases.

This study had certain limitations. It is the first study carried out in Aden based on doctors' satisfaction for the services provided by hospital clinical laboratories and we faced a rather poor level of cooperation of doctors to complete the questionnaire in a reasonable time. Although the response rate in this survey was only $78 \%$, this is, nevertheless, within the range reported by other studies $(65.5 \%-85.6 \%)$ [11-13].

The study was done in only 1 city in Yemen (as reflected in the title) and may not represent the situation in the country as a whole. The study sample was calculated to be representative of Aden Governorate hospitals.

\section{Acknowledgements}

Funding: This study did not receive any funding.

Competing interests: None declared.

\section{References}

1. Mfinanga SG et al. Patient's dissatisfaction with the public and private laboratory services in conducting HIV related testing in Tanzania. BMC Health Services Research, 2008, 8:167-171.

2. Workbook 6. Client Satisfaction Evaluations. Geneva, World Health Organization, 2000 (WHO/MSD/MSB 00.2g) (http:// whqlibdoc.who.int/hq/2000/WHO_MSD_MSB_00.2g.pdf, accessed 2 April 2013).

3. Jones BA et al.; College of American Pathologists. Physician satisfaction with clinical laboratory services: a College of American Pathologists Q-probes study of 138 institutions. Archives of Pathology \& Laboratory Medicine, 2009, 133:38-43.

4. Morales E, Hattab AS, Reinoso T. Health Statistics and Research Methodology. 2nd ed. Aden: University Printing and Publishing House; 2002.

5. Miller KA, Dale JC. Physician satisfaction with clinical laboratory service. Q-Probes (99-03). Northfield, Illinois, College of American Pathologists, 1999:1-10.

6. Zarbo RJ, Nakhleh RE, Walsh M; Quality Practices Committee, College of American Pathologists. Customer satisfaction in anatomic pathology. A College of American Pathologists Q-Probes study of 3065 physician surveys from 94 laboratories. Archives of Pathology \& Laboratory Medicine, 2003, 127:23-29.
7. Kairys J et al. Satisfaction with organizational aspects of health care provision among Lithuanian physicians. Central European Journal of Public Health, 2008, 16:29-33.

8. Human development indices. New York, Human Development Report Office, United Nations Development Programme, 2008 (http://hdr.undp.org/en/media/HDI_2008_EN_Tables.pdf, accessed 28 April 2013).

9. World Health Report 2000 - Health Systems: Improving Performance (Statistical Annex). Geneva, World Health Organization, 2000 (http://www.who.int/whr/2000/en/whr00_annex_ en.pdf, accessed 28 April 2013).

10. Mfinanga SG et al. Dissatisfaction with the laboratory services in conducting HIV related testing among public and private medical personnel in Tanzania. BMC Health Services Research, 2008, 11(8):171.

11. Abdel-Rahman AG et al. Low job satisfaction among physicians in Egypt. TAF Preventive Medicine Bulletin, 2008, 7(2):91-96.

12. Madaan N. Job satisfaction among doctors in a tertiary care teaching hospital. JK Science: Journal of Medical Education \& Research, 2008, 10 (2):81-82.

13. Buciuniene I, Blazeviciene A, Bliudziute E. Health care reform and job satisfaction of primary health care physicians in Lithuania. BMC Family Practice, 2005, 6(1):10. 